\title{
Snuff Dipping Sudanese Tombak Keratosis - A Case Report
}

\section{Yousif | Eltohami, Nour E Alim and Amal H Abuaffan}

Faculty of Dentistry, University of Khartoum, Sudan

Corresponding author: Amal H. Abuaffan, Faculty of Dentistry, University of Khartoum, Sudan, Tel: +249 917481188 ; E-mail: amalabuaffan@yahoo.com

Rec Date: January 28, 2017, Acc Date: March 22, 2017, Pub Date: March 24, 2017

Citation: Eltomahi YI, Alim NE, Abuaffan AH. Snuff Dipping Sudanese Tombak Keratosis - A Case Report. Med Cas Rep. $2017,3: 1$.

\section{Abstract}

Oral smokeless tobacco is consumed without burning, placed in many areas in the oral cavity especially labial vestibules. In Sudan, it's widely practiced among young population; it can give rise to sub-mucous fibrosis, leukoplakia, snuff dipper's lesion, squamous cell carcinoma. The current case report has typical features of snuff dippers lesions (keratosis) in a young Sudanese male who had history of smokeless tobacco dipping in the labial vestibules for a long term.

Keywords: Keratosis; Pre-cancerous; Snuff dipper's lesions; Smokeless tobacco

\section{Introduction}

Globally smokeless tobacco can be found either as snuff or chewing tobacco. Snuff could be dry or moist. Moist snuff is usually taken orally [1]. The incidence and the severity of the lesions depend on the dose-response, which is depending on the quantity, duration and frequency of the habit use [2]. The majority of keratotic lesions arised from snuff dipping are reversible within two to six weeks after quitting of the snuffing, if the oral lesion does not resolve after that, then an incisional biopsy from the suspicious area (mostly gingivo-labial vestibule) should be done followed by treatment of the patient according to the histopathologial findings $[3,4]$.

\section{Case Report}

A 37-year-old Sudanese male came to Oral and Maxillofacial Surgery Clinic complaining from changes in the labial mucosa and gum, painless that discovered incidentally during routine oral screening.

Patient's medical history he was fit with no significance, he was smoker for 12 years, snuff dipping for more than 20 years (patient did not rinse after use the snuff and sleep with it) and patient denied any history of alcohol abuse.

On clinical examinations, there was a painless white-grayish mucosal roughness, folding, corrugations and snuff dipping pouch in the gingiva and lower labial mucosa and in the left side of the upper labial mucosa (Figures 1 and 2). There were no palpable submandibular or cervical lymph nodes.

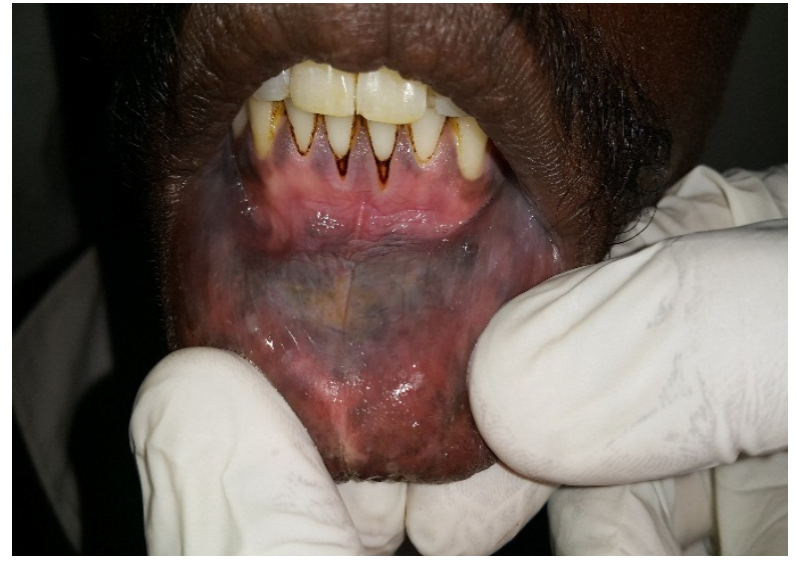

Figure 1 Shows a white-yellowish and grayish mucosal roughness and snuff dipping pouch in the gingiva and lower labial mucosa.

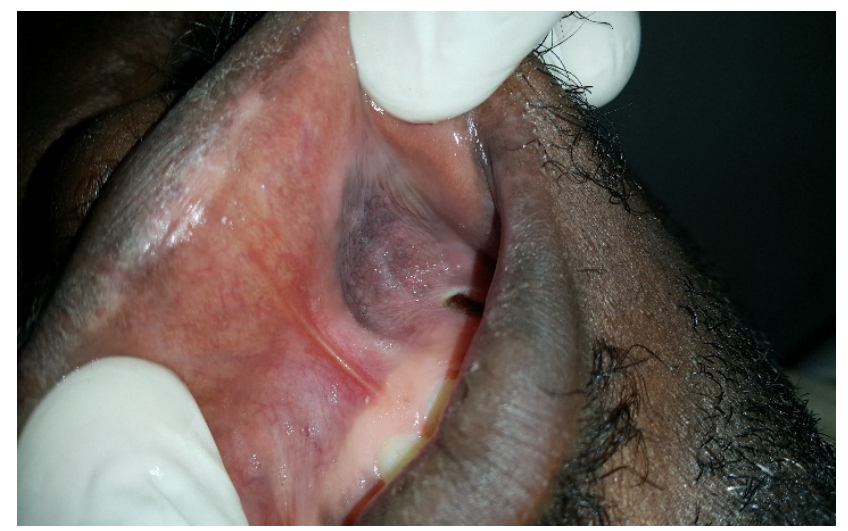

Figure 2 Shows white-grayish mucosal roughness, corrugations and snuff dipping pouch in the gingiva and left upper labial mucosa.

An incisonal biopsy was taken, Histopathological examination showed hyperkeratosis, acanthosis and fibrosis without any evidence of dysplasia or cellular atypia. Diagnosis of tobacco pouch keratosis was given. 
Patient was advised and instructed for habits quitting and schedule for regular follow-up.

\section{Discussion}

The keratotic lesions clinically appear variable depending on the type of tobbaco used, the frequency and duration of use [5]. A four-degree scale clinical features of smokeless tobaccoinduced lesion that was introduced by Axell and colleagues, [6] and is still used by Roosaar et al. [7]. They include:

Grade I: A similar color to the mucosa that surround it, superficial lesion with slight wrinkling and no thickening.

Grade II: A whitish or yellowish lesion, superficial with wrinkling and no thickening.

Grade III: A whitish yellow or brown wrinkling intervening furrow of normal mucosal color with thickening.

Grade IV: A marked whitish- yellow to brown, obvious heavy wrinkling with intervening deep and reddened furrows or heavy thickening.

In this patient grade III and IV was observed. There's strong correlation between snuff dipping and the prevalence of snuff dipping keratosis, it is widely practised among sudanese population, in literature it had been reported that $60 \%$ of snuff users will develop smokeless tobacco keratosis $[3,8]$.

Toombak is a moist snuff tobacco well known in Sudan, it is made from a tobacco species with a high content of nicotine and minor alkaloids, and then it is mixed with atron (sodium bicarbonate) and water, after a period of time the mixture, called "Saffa" [9]. The nitrose amines levels that found in Tobacco are high in toombak [10], attributed to the type of tobacco Species and way of processing toombak at high temperature, prolonged storage, and contamination during processing [11-13]

Smokeless tobacco use delivers more nicotine to the body as cigarette smoking do, and it can irritate the mucosa of the mouth and esophagus [14].

In 2007, the agency that responsible in research cancer released a report concluding that smokeless tobacco is a known human carcinogen, causing oral cancer and pancreas (IARC 2007) [15].

The literature review dedicated that the malignant transformation of the smokeless tobacco is not common. Dysplasia in smokeless tobacco keratosis is quiet rare accounts for less than $3 \%$ of cases; which is a condition that precedes and often indicates malignancy potentiality [6,16-18]. A retrospective study in Sweden found only one case of malignant transformation, an extremely low frequency [19]. Hence a periodic follow up and meticulous clinical examination is mandatory.

The treatment of smokeless tobacco keratosis first is to advice the patient to discontinue using tobacco, second keeping the regular follow up appointments.

\section{Conclusion}

Tobacco use in any form, smoking or smokeless continues to be practiced by many people in Sudan. Smokeless tobacco use is about twice as high as smoking. Worldwide it is approved that smokeless tobacco use is associated with precancerous lesions that may lead to increase the mortality and morbidity if not discovered and managed early. Hence more awareness among the people and stricter rules and regulations are needed to reduce this habit.

\section{References}

Walsh PM, Epstein JB (2000) The oral effects of smokeless tobacco. J Can Dent Assoc 66: 22-25.

Little SJ, Stevens VJ, LaChance PA, Severson HH, Bartley MH, et al. (1992) Smokeless tobacco habits and oral lesions in dental patients. J Public Health Dent 52: 269-276.

Neville BW, Day TA (2002) Oral cancer and precancerous lesions. CA Cancer J Clin 52: 195-215.

4. Neville BW, Damm DD, Allen CM, Bouguot JE (2004) Oral and maxillofacial pathology, (2ndedn), WB Saunders Company Ltd, Pennysylvania, USA p: 635-637.

5. Werning JW (2011) Oral cancer: Diagnosis, management, and rehabilitation. p: 12-13.

6. Axell T (1976) A prevalence study of oral mucosal lesions in an adult Swedish population. Odontol Revy 27: 100-103.

7. Roosaar A, Johansson ALV, Sandborgh-Englund G, Nyrén O, Axéll $T$ (2006) A long-term follow-up study on the natural course of snus-induced lesions among Swedish snus users. Int J Cancer 119: 392-397.

8. Rodu B, Jansson C (2004) Smokeless tobacco and oral cancer: A review of the risks and determinants. Crit Rev Oral Biol Med 15: 252-263.

9. Idris AM, Ahmed HM, Mukhtar BI, Gadir AF, El-Beshir El (1995) Descriptive epidemiology of oral neoplasms in Sudan 1970-1985 and the role of toombak. Int J Cancer 61: 155-158.

10. Idris AM, Nair J, Ohshima H, Friesen M, Brouet I, et al. (1991) Unusually high levels of carcinogenic tobacco-specific nitrosamines in Sudan snuff (toombak). Carcinogenesis 12: $1115-1118$.

11. Andersen RA, Burton HR, Fleming PD, Hamilton-Kemp TR (1989) Effect of storage conditions on nitrosated, acylated, and oxidized pyridine alkaloid derivatives in smokeless tobacco products. Cancer Res 49: 5895-5900.

12. Djordjevic MV, Fan J, Bush LP, Brunnemann KD, Hofmann D (1993) Effects of storage conditions on levels of tobacco specific $\mathrm{N}$ nitrosamines and $\mathrm{N}$ nitrosaminoacids in US moist snuff. J Agr Food Chem 11: 1790-1794.

13. Prokopczyk B, Wu M, Cox JE, Hoffmann D (1992) Bioavailability of tobacco-specific $\mathrm{N}$ nitrosamines to the snuff dipper. Carcinogenesis 13: 863-866.

14. Ray CS, Gupta PC (2009) Bidis and smokeless tobacco. Current Science 96: 1324-1334.

15. International Agency for Research on Cancer (IARC) (2007) Smokeless tobacco and some tobacco-specific N-nitrosamines. 89 Lyon, France. 
16. Smith JF, Mincer HA, Hopkins KP, Bell J (1970) Snuff-dipper's lesion. A cytological and pathological study in a large population. Arch Otolaryngol 92: 450-456.

17. Roed-Petersen B, Pindborg JJ (1973) A study of snuff induced oral leukoplakias. J Oral Pathol 2: 301-313.
18. Bouquot J, Schroeder K (1993) Oral leukoplakia and smokeless tobacco keratoses are two separate and distinctive pre-cancers. Oral Surg 76: 588-589.

19. Axéll T, Mornstad H, Sundström B (1978) Snuff and cancer of the oral cavity. A retrospective study. Läkartidningen 75: 1224-1226. 